\title{
Articulando os Espaços Público e Privado: Transformações das Espacialidades Vividas por Mulheres Moradoras de Periferias Pobres Após a Dissolução Conjugal na Cidade de Ponta Grossa - PR
}

\author{
Linking Public and Private Spaces: Transformations of the Spatiality Experienced \\ by Head of Household Women After Marital Dissolution in the City of \\ Ponta Grossa - PR
}

\author{
Juliana Przybysz \\ Universidade Estadual de Ponta Grossa \\ juliana.przybysz@gmail.com \\ Joseli Maria Silva \\ Universidade Estadual de Ponta Grossa \\ joseli.genero@gmail.com
}

Resumo

Este trabalho tem por objetivo compreender as transformações das espacialidades vividas por mulheres responsáveis pelo domicilio após a dissolução conjugal na cidade de Ponta Grossa - PR. Os processos de dissolução conjugal e a guarda feminina dos filhos do casal tem instituído famílias em que se destaca a chefia das mulheres. Embora o fenômeno seja comum em todas as faixas de rendimento, as famílias moradoras de periferias pobres constituem um grupo vulnerável ao empobrecimento e fragilização aos direitos cidadãos. Para cumprir o objetivo da pesquisa foi realizado um levantamento dos processos da Segunda Vara de Família de Ponta Grossa, nas categorias de Separação, Divórcio e Alimentos no período de 2003 a 2007, envolvendo famílias entre zero e dois salários mínimos com filhos menores de quatorze anos de idade na época da separação. Foram selecionados quinhentos e vinte e dois processos, relativos ao recorte social estabelecido e efetivada uma análise segundo categorias chave. Foram também, realizadas dezessete entrevistas com mulheres chefes de família, a partir de um roteiro de entrevista semiestruturado. As espacialidades vivenciadas por mulheres chefes de família se modificam após a separação conjugal, articulando de forma diversa as esferas pública e privada do espaço urbano.

Palavras - Chave: Gênero; articulação público / privado; dissolução conjugal.

\begin{abstract}
This paper aims to understand the transformation of the spatialities experienced by female heads of household after marital dissolution, in the city of Ponta Grossa - PR. The processes of marital dissolution and the female custody of the couple's children has established families in which women's leadership is highlighted. Although this phenomenon is common in all ranges of income, families living in poor neighborhoods are a vulnerable group to impoverishment and to the weakening of civil rights. To fulfill the objective of this research, we performed a survey of the processes of the Second Family Court of Ponta Grossa, in the categories of Separation, Divorce and Maintenance, from 2003 to 2007, involving families earning from zero to two minimum wages, with children under twelve years of age. We selected five hundred twenty-two processes related to the social divisions chosen and accomplished an analysis according to key categories. We also conducted interviews with seventeen women who are heads of households, from a semi-structured guideline. The spatiality experienced by head of household women is modified after the divorce, so it diversely articulates the public and private spheres of urban space.
\end{abstract}

Keywords: Gender; public/private space; marital dissolution. 


\section{Introdução}

O objetivo deste trabalho é compreender as transformações das espacialidades vividas por mulheres responsáveis pelo domicílio após a dissolução conjugal na cidade de Ponta Grossa - PR. O aumento da pobreza e da presença de mulheres chefes de família nas periferias das cidades vêm chamando a atenção da sociedade e da comunidade científica. A constituição de famílias chefiadas por mulheres tem como um de seus principais fatores as dissoluções conjugais que impõem novas organizações do grupo familiar.

Para fundamentar os argumentos do artigo, foram analisados quinhentos e vinte e dois processos da Segunda Vara de Família na cidade de Ponta Grossa PR, nas categorias de Divórcio, Separação e Alimentos, entre os anos de 2003 e 2007, com recorte temporal estipulado a partir da entrada em vigor do Novo Código Civil em 2003 ${ }^{1}$. Foram selecionados os processos que envolviam famílias na faixa de sem rendimento até dois salários mínimos com filhos menores de quatorze anos de idade na época da instauração do processo. Além disso, foram realizadas dezessete entrevistas qualitativas com mulheres que passaram por dissolução conjugal, moradoras dos conjuntos habitacionais com maior concentração de mulheres chefes de família em Ponta Grossa - PR. Foram considerados Jardim Alto Alegre com 47\% de mulheres chefes de família, Jardim Jacarandá com a presença de $29 \%$ e Jardim Cerejeiras com 24\%. As entrevistas foram sistematizadas por meio de técnicas de análise de conteúdo, considerando a frequência dos enunciados utilizados pelas pessoas entrevistadas que constituíram eixos de categorias reunidas por significados semânticos conforme a proposta de Bardin (2002).

O trabalho está estruturados em três seções. $\mathrm{Na}$ primeira, foram explicitadas as relações existentes entre os papéis de gênero nos agrupamentos familiares e as possibilidades da análise geográfica dessas categorias. A segunda, traz a realidade vivenciada pelas mulheres de baixa renda que passam por processos de dissolução conjugal e a reestruturação de sua vivência cotidiana ao assumir a guarda dos filhos menores. $\mathrm{Na}$ terceira e última parte, são analisadas as experiências espaciais femininas das famílias reestruturadas em periferias pobres urbanas, evidenciando a necessidade de uma abordagem relacional entre os espaços público e privado.

\section{Espaço, Dissoluções Conjugais e Representações de Gênero nos Agrupamentos Familiares}

O espaço das cidades pode ser concebido de diversas maneiras na geografia, dependendo de sua abordagem epistemológica e da construção da inteligibilidade do fenômeno a ser investigado no processo de pesquisa. A tradição geográfica crítica no Brasil esteve preocupada em compreender as formas de organização da produção, da divisão do trabalho e da distribuição da riqueza socialmente produzida que traz sentido para ordem espacial capitalista e desigual presente nas sociedades ocidentais, como pode ser visto nas obras de Santos (1985 e 1987) e Corrêa (2003). Embora tais abordagens tenham construído importante caminho interpretativo para as desigualdades de acesso aos bens e serviços urbanos por diversos grupos sociais, há ainda várias lacunas a serem vencidas no que diz respeito aos aspectos distributivos de recursos econômicos, sociais e ambientais. Uma delas, está relacionada ao gênero que perpassa outras importantes categorias sociais como a raça, a renda e a idade.

A sociedade em seu aspecto espacial não pode ser tomada apenas por suas diferenças de rendimentos, já que há outras formas de hierarquização de grupos que se aliam aos fatores econômicos e conformam a complexidade da vida social. Corrêa e Rosendahl (2003) argumentam que os aspectos culturais são fortes elementos a serem considerados na concepção do espaço. Entre as variadas abordagens possíveis no campo da geografia cultural, a corrente chamada Nova Geografia Cultural constrói abordagens teóricas e metodológicas capazes de contemplar as diferenças entre variados grupos sociais, considerando aspectos raciais, sexuais, gênero, idade, religião, entre outros. Essa corrente científica elabora a ideia de que não há significados contidos no espaço, mas que cada grupo social, por meio de suas experiências, cria significados próprios que se diferenciam dos demais grupos. Portanto, é possível afirmar que a experiência humana marcada pelo gênero, vivenciado cotidianamente, posiciona pessoas de forma hierarquizada socialmente, conforme os valores de cada sociedade. Tais valores constituem contextos em que se oportunizam privilégios e opressões.

Nesse sentido, o espaço urbano, além de produzido política e economicamente, é constituído também por meio das experiências generificadas vivenciadas no cotidiano das pessoas. Ao contrário da pretensa neutralidade do espaço urbano relativa aos papéis de gênero, Hidalgo, Juliano, Roset e Caba (2003) 
afirmam que houve uma supremacia conceitual sobre as cidades em que se privilegiou a versão conceitual masculina, dificultando a visibilidade das relações de gênero que também compõem o espaço urbano. Há, na tradição linguística da produção geográfica brasileira a visão de uma sociedade genérica, apenas caracterizada pelas classes sociais que escamoteia a análise das pessoas que são conformadas também pela cor da pele, gênero e sexualidade, como argumentam Silva, Chimin Junior, Peracetta Filho e Rossi (2009).

$\mathrm{O}$ acolhimento das diferenças elencadas pelos autores na perspectiva espacial pode ser concebida por meio das proposições de Massey (2008, p. 49). Para ela, o espaço é produto de relações abertas através de multiplicidades ou como 'uma simultaneidade de estórias-até-agora'. Essa proposição possibilita a abordagem da complexidade, de um espaço em movimento constante, vivo, aberto, heterogêneo e político.

Toda existência humana é generificada e isso implica que o gênero atribuído socialmente aos seres humanos gera papéis sociais fortemente regulados, inclusive pelo poder jurídico de Estado. Os papéis sociais de homens e mulheres constituem formas diferentes de relações espaciais que estão profundamente enraizados no processo de reprodução social que em nossa sociedade se funda na organização familiar, ainda vinculada à ordem compulsória heterossexual. A união conjugal entre homens e mulheres cria e recria constantemente os papéis de gênero a serem desempenhados e expressam as expectativas sociais quanto à constituição familiar. Entretanto, na medida em que há qualquer desmantelamento das relações que envolvem o padrão familiar, mudam os papéis vivenciados e consequentemente, suas espacialidades, como é o caso das dissoluções conjugais, foco dessa análise.

Assim, o gênero, como afirma Veleda da Silva (2009, p. 306), é uma categoria:

útil à geografia para entendermos determinados fenômenos e/ou processos geográficos, mas a perspectiva feminista vai além desta categoria e amplia o leque de possibilidades de se produzir um conhecimento comprometido com mudanças sociais. Um conhecimento engajado na luta pelo fim das desigualdades sociais produzidas por relações sociais de sexo hierarquizadas.

Embora se saiba que há uma multiplicidade de abordagens do conceito de gênero nas geografias feministas que estão presentes nas correntes estruturalistas e pós-estruturalistas, como apontado em Silva (2009), esse trabalho está fundamentado na ideia do gênero concebido como uma representação social de papéis a serem desenvolvidos por corpos compreendidos como masculinos e femininos diferenciados temporal e espacialmente. Conforme Butler (2003), as representações de gênero não existem em si, como uma essência, mas ganham concretude nas práticas cotidianas das pessoas. Tais práticas de gênero criam a falsa impressão de uma permanência dos papéis de gênero que, no entanto, são constantemente subvertidos em movimentos constantes.

Se o gênero é uma representação social que os corpos humanos experienciam temporalmente e espacialmente, o espaço é também conformado por tais práticas. Contudo, entre as práticas cotidianas que possibilitam as subversões dos papéis hegemonicamente instituídos socialmente, há um forte caráter regulatório na esfera jurídica que impõe regras sociais associadas ao gênero na conformação das organizações familiares. A ordem estatal ${ }^{2}$ considera a família como um agrupamento composto por homem/pai, mulher/mãe e filhos/filhas. Embora a vida cotidiana tenha evidenciado a possibilidade de inúmeras outras formas de organizações familiares, que escapam do modelo hegemônico instituído, a regulação de Estado prima pela organização da família com caráter reprodutivo e papéis sociais bastante definidos socialmente entre homens e mulheres. $\mathrm{O}$ rompimento dessa organização por meio das dissoluções conjugais provoca um rearranjo familiar que influencia também nos papéis de gênero.

A família não é uma entidade fixa, mas construída socialmente em diferentes tempos e espaços que assume um modelo hegemônico instituído pelo Estado. Sendo assim, a construção social da família é dinâmica e apresenta tensões ao modelo hegemônico que sofre transformações, conforme Sorj (2004).

As dissoluções conjugais rearranjam os papéis sociais instituídos, notadamente nas famílias de baixa renda, moradoras de periferias pobres. Os escassos recursos existentes para a manutenção familiar tornamse ainda mais raros após a reorganização da família e, em geral, isso afeta notadamente o papel feminino que majoritariamente assume a guarda dos filhos do casal. Nesse sentido, a dissolução conjugal ocorrida em famílias de baixa renda possui consequências diferentes para homens e mulheres e por conseguinte, altera os padrões de espacialidades anteriormente estabelecidos.

O papel da maternagem ${ }^{3}$ é atribuído tradicionalmente às mulheres, conforme argumenta Badinter (1985), bem como os cuidados com a família

Juliana Przybysz e J oseli Maria Silva 
e a casa. Apesar de todo o avanço da absorção do trabalho feminino na sociedade contemporânea, Hidalgo, Juliano, Roset e Caba (2003) afirmam que a entrada das mulheres no mercado de trabalho não retirou sua carga de responsabilidade no espaço privado e o que se tem configurado é um aumento expressivo de horas trabalhadas pelas mulheres, evidenciando pequenas transformações na divisão sexual do trabalho no processo de reprodução familiar.

As vivências das espacialidades da casa, consideradas como domínio particular e privado, estão colocadas em oposição ao espaço que se tem considerado como 'espaço público'. O espaço público tem sido privilegiado na análise geográfica em detrimento ao espaço privado, como pode ser visto em Mitchell (1996) e Goheen (1998). No Brasil, as proposições de Gomes (2002) seguem a mesma tendência. Entretanto, Souza (2006, p. 110) elabora um interessante pensamento sobre a necessidade de pensar escalarmente os espaços de forma articulada dizendo que "pensar espacialmente diz respeito, igualmente, à capacidade de perceber e articular as várias escalas em que os processos sociais emergem e operam, do local inclusive no nível mais micro, como o bairro ou mesmo no nível do espaço privado e familiar - ao global".

A abordagem das interdependências entre o público e o privado que a geografia pode oferecer é por meio da análise escalar que ultrapasse a noção de hierarquia de categorias - público-privada-, mas que permita a concepção relacional de ambas, como propõe Howit (1998), Marston (2000) e Sheppard e McMaster (2004). Assim, por meio de uma abordagem escalar relacional e não hierarquizada entre espaço público e privado pode-se criar análises geográficas de agrupamentos sociais como as famílias, tradicionalmente vinculadas à esfera privada e por isso, negligenciadas pela geografia brasileira.

A dicotomia entre privado e público não existe em si, mas foi construída pela comunidade científica como uma forma de compreender o mundo e produzir visibilidade de alguns aspectos da vida social em detrimento de outros. A ideia de que o espaço privado possibilita a realização da liberdade individual e o espaço público da neutralidade para o exercício da civilidade colocou vários temas fora do escopo de discussões políticas de justiça, como são várias relações como é o caso do gênero, da família e da sexualidade, conforme Assis (2009).

Arendt (2007) argumenta a necessidade de superação da dicotomia das esferas pública e privada nos processos sociais contemporâneos, pois, segundo ela: a contradição entre o público e o privado, típica dos estágios iniciais da era moderna, foi um fenômeno temporário que trouxe a completa extinção da própria diferença entre as esferas privada e pública, a submersão de ambas na esfera do social (ARENDT, 2007, p. 79).

A autora chama a atenção para as relações de complexidade e de interdependência que devem permear a visão do mundo contemporâneo. No campo da geografia esse apelo tem sido realizado pelas correntes feministas como Massey (2008), McDowell (1999) e Rose (1993). As geógrafas dessa corrente têm criticado a formulação de conceitos e tradições epistemológicas que impossibilitam construir a visibilidade do mundo feminino e a construção da dicotomia entre os espaços públicos e privados é um dos caminhos trilhados pela supremacia do conhecimento masculino em detrimento ao feminino.

Rose (1993) pautada pelas ideias de superação das dicotomias que marcam a ciência produzida pelos homens criou a ideia do espaço paradoxal que envolve profunda análise relacional entre dimensões sociais e escalas espaciais. Ela argumenta que cada pessoa ou grupo social vivencia várias dimensões da vida social de forma simultânea e que, por isso, também está localizada em diversas posições, dependendo das relações que se estabelecem em forma de feixes que não são fixos, mas móveis. $O$ espaço paradoxal se define por constituir uma dinâmica espacial móvel, tensionada por relações de poder, multidimensional e plurilocalizada, sendo conformado situacionalmente, deslocando sujeitos em movimentos de centro e margem das relações de poder.

As proposições de Rose (1993) possibilitam construir uma análise geográfica em torno das transformações das espacialidades vividas por mulheres responsáveis pelo domicilio após a dissolução conjugal, foco desse trabalho. Por exemplo, o espaço privado pode ser vivenciado pelas mulheres de forma que ela ocupe uma posição central em relação ao seu marido e filhos e uma posição periférica em relação ao espaço público. Entretanto, ela vivencia ambas as espacialidades, em movimento constante no curso de sua vida. No caso da dissolução conjugal, a mulher que já ocupava uma posição de centralidade na vida doméstica, deverá lutar para melhorar seu desempenho no espaço público, no sentido de produzir maior rendimento econômico para o sustento da família reconfigurada com a ausência do cônjuge. $\mathrm{O}$ 'movimento' de múltiplas espacialidades, com uma multiplicidade de acontecimentos é vivenciado de forma simultânea em ambas as esferas, pública e

Juliana Przybysz e J oseli Maria Silva 
privada, integrando-as e transformando-as de forma relacional.

\section{Dissoluções Conjugais e a Responsabilidade Feminina na Reestruturação Familiar nas Periferias Pobres}

A regulação Estatal dos agrupamentos sociais que são considerados famílias sofreram modificações ao longo da história social brasileira com a emancipação feminina, a solubilidade do matrimônio, o reconhecimento das uniões estáveis tanto hetero como homoafetivas foram movimentos importantes nas configurações das famílias brasileiras. Os papéis sociais de cada um dos componentes familiares também se modificou e as questões de gênero e da divisão sexual do trabalho familiar esteve no centro dessas transformações.

Féres-Carneiro (2001) argumenta em seu estudo que embora as mulheres tenham transformado sua atuação no mercado de trabalho, a manutenção dos afazeres da casa e dos cuidados com a família ainda fundam a identidade feminina no mundo atual. Segundo ela, não houve uma alteração significativa da divisão do trabalho doméstico entre homens e mulheres com a mesma intensidade com que as mulheres ocuparam os postos de trabalho fora de suas casas. Seu estudo evidencia que os homens desempenham tarefas domésticas esporadicamente ou desempenham um papel de 'ajuda' às mulheres nas tarefas de reprodução familiar pois elas ainda são as principais responsáveis pelo trabalho doméstico. Por outro lado, o trabalho feminino que gera uma contribuição financeira para o sustento econômico da família também é considerada uma 'ajuda' aos homens, pelo fato de sua remuneração ser menor, comparada com a dos homens.

Embora os mundos masculino e feminino, no período contemporâneo, estejam mais fluídos, há ainda elementos culturais ligados aos papéis de gênero que vinculam as mulheres à centralidade das famílias e da casa que é profundamente desestabilizado em processos de dissoluções conjugais nas famílias de baixa renda que vivem com escassos recursos econômicos e a separação do casal gera ainda mais carências. Notadamente, porque a 'natural aptidão feminina' faz com que as mulheres assumam a guarda dos filhos após a separação dos cônjuges na maioria dos casos.

As dissoluções conjugais desestabilizam as relações de gênero instituídas familiarmente e exigem novas negociações e desempenhos sociais dos ex- cônjuges. As dissoluções conjugais tem sido elemento de constituição de famílias chefiadas por mulheres e em geral, segundo o Instituto Brasileira de Geografia e Estatística, em 2010, as mulheres que são responsáveis pela família sem o cônjuge tem a renda $13,66 \%$ menor do que os homens que são responsáveis pela família sem cônjuge. $\mathrm{Na}$ cidade de Ponta Grossa, esse percentual é ainda maior. A renda das mulheres que são responsáveis pela família sem cônjuge é $15,3 \%$ menor do que a do homem na mesma situação.

A forte constituição da identidade feminina de mulheres de baixa renda em torno da família e do trabalho doméstico, conforme identificado no trabalho de Silva (2007) geram pequenas perspectivas de qualificação para o mercado de trabalho que passa a ser um importante elemento na reconfiguração familiar após a dissolução conjugal das camadas de baixa renda.

Do total de quinhentos e vinte e dois processos processos analisados na $2^{\mathrm{a}}$ Vara de Família em Ponta Grossa $^{4}$ no período de 2003 e 2007, 34\% das mulheres eram donas de casa enquanto que $66 \%$ das mulheres trabalhavam em atividades ligadas ao espaço privado como limpeza, cozinha, cuidados com crianças e idosos. Esta tendência encontrada nos processos foi confirmada no trabalho de campo durante a realização das entrevistas nos conjuntos habitacionais selecionados.

A desqualificação e inexperiência para enfrentar o mercado de trabalho após a dissolução conjugal alia-se ao fato de que são as mulheres que assumem a guarda dos filhos em 96,3\% dos processos analisados. Tal combinação de fatores trazem consequências específicas ao universo de mulheres moradoras de periferias que acabam por não obter do pai de seus filhos a manutenção financeira após a dissolução conjugal. $\mathrm{Na}$ maior parte das vezes, as mulheres acabam assumindo sozinhas o sustento econômico da família no processo de reestruturação familiar. Esse fenômeno fica claro na análise da relação entre as Ações de Alimentos e de Execução de Alimentos. Para cada ação de Alimentos solicitadas aos pais, existem 0,72 ações de Execuções de Alimentos, ou seja, 71\% dos pedidos de Alimentos não foram cumpridos pelos pais e o Estado teve que executar a ação. Nas entrevistas em campo, os resultados obtidos foram muito semelhantes em relação ao abandono financeiro masculino. $50 \%$ das mulheres entrevistadas não recebem ajuda financeira para o cuidado dos filhos e $26 \%$ recebem ajuda financeira esporádica. Apenas $24 \%$ alegam ter ajuda financeira regular.

Recorrer ao poder judiciário para obter ajuda dos pais de seus filhos no sustento financeiro da família não tem surtido efeito desejado por elas. As entrevistas

Juliana Przybysz e J oseli Maria Silva 
realizadas evidenciam que elas possuem muitas dificuldades para acessar o sistema jurídico. $56 \%$ das falas das mulheres entrevistadas evidenciam que elas procuraram a justiça. Contudo, $82 \%$ das evocações referem-se a uma experiência negativa com a justiça e apenas $18 \%$ das falas referem-se a uma experiência positiva.

O sistema jurídico brasileiro não é acessível às mulheres de baixa renda, mesmo quando elas conseguem realizar ações por meio de uma assessoria gratuita. Isso porque o sistema tem como base de atuação um modelo familiar com endereço fixo e trabalho formal dos pais que são objeto da ação de alimentos. Contudo, nas periferias pobres em que a mobilidade residencial é imensa, bem como a instabilidade do trabalho, faz com que boa parte das pessoas sequer sejam encontradas para discutir juridicamente as necessidades de sustento dos filhos menores de famílias dissolvidas o que culmina com o arquivamento dos processos.

Nos duzentos e vinte e cinco processos de Separação e Divórcio analisados a partir das petições iniciais foi possível detectar as queixas feitas pelas mulheres após a dissolução conjugal que foram reunidas em quatro categorias apresentadas no quadro 1.

Quadro 1 - Queixas feitas pelas mulheres após a dissolução conjugal nos processos de Separação e Divórcio.

\begin{tabular}{|l|c|c|}
\hline \multicolumn{2}{|c|}{ Queixas feitas pelas mulheres após a dissoluçāo conjugal } \\
\hline \multicolumn{1}{|c|}{ Tipo de dificuldade relatada } & $\begin{array}{c}\text { Número de Ocorrências de } \\
\text { Queixas nos processos } \\
\text { investigados }\end{array}$ & \% de representaçào das queixas \\
\hline $\begin{array}{l}\text { Abandono econômico dos } \\
\text { filhos }\end{array}$ & 89 & $53,60 \%$ \\
\hline $\begin{array}{l}\text { Mudança de residência e } \\
\text { dependência dos } \\
\text { pais/avós/parentes }\end{array}$ & 44 & $26,50 \%$ \\
\hline $\begin{array}{l}\text { Falta de visitas e abandono } \\
\text { afetivo }\end{array}$ & 17 & $10,30 \%$ \\
\hline Outras queixas & 16 & $9,60 \%$ \\
\hline Total & $\mathbf{1 6 0}$ & $\mathbf{1 0 0} \%$ \\
\hline
\end{tabular}

Fonte: $2^{\mathrm{a}}$ Vara de Família

Organização: Juliana Przybysz

O maior número de queixas realizadas pelas mulheres relaciona-se ao abandono econômico dos filhos. Em segundo lugar, aparece a categoria mudança de residência e dependência dos pais/avós/parentes, em terceiro, falta de visitas e abandono afetivo e em quarto lugar está a categoria 'outras queixas'.

As mulheres queixam-se que os ex-cônjuges não prestam ajuda financeira aos filhos, sendo que sua baixa capacidade de gerarem renda nas periferias tem causado carências extremas, inclusive de alimentos básicos. Essas mulheres acabam contando com a ajuda dos avós ou parentes que acolhem a família reestruturada. Os avós são em geral, os maternos. A avó materna é a figura mais frequente que arca com o ônus do sustento e abrigo das famílias monoparentais de baixa renda. $\mathrm{O}$ abandono afetivo está relacionado à 
falta de visitas e de contato com os filhos e na categoria chamada de 'outras' estão reunidas aquelas de baixa frequência de relatos como casos de abuso sexual em relação aos filhos, maus tratos, tentativa de controle do corpo em relação a ex-companheira e má conduta moral.

Os processos analisados provenientes de dissoluções conjugais e ações de alimentos de famílias de baixos rendimentos evidenciam um fenômeno de feminização de chefias familiares que constituem grupos de alta vulnerabilidade social. A dissolução conjugal de um grupo social de escassos recursos econômicos gera a reorganização de famílias em torno unicamente das mulheres que mantém a guarda dos filhos. Esse tema é escamoteado da arena pública e tratado apenas como falta de responsabilidade paterna dentro de uma ordem privada. Esse fenômeno social, ao contrário, é tema de ordem pública e exige estratégias específicas de enfrentamento para minimizar a vulnerabilização dos agrupamentos familiares reorganizados após as dissoluções conjugais nas periferias pobres do Brasil.

\section{As Experiências Espaciais Femininas nas Periferias Pobres: Articulando os espaços público e privado}

A reprodução social por meio de famílias moradoras de periferias pobres ocorre por meio de uma divisão sexual do trabalho, a qual está profundamente relacionada com a estrutura urbana. Como lembra Souza (2006), há uma relação entre as escalas espaciais que viabilizam a vida cotidiana. O cuidado com a infância é pouco compreendido como uma responsabilidade pública, mas privada, de ordem familiar. Nas famílias moradoras de periferias em que não há creches, escolas, postos de saúde e os serviços de transporte são deficitários, são as mulheres, responsáveis pelo trabalho doméstico e o cuidado familiar, que sofrem as maiores privações. São elas que se organizam para o cuidado das crianças em torno de redes de vizinhas e parentes, enfrentam a intermináveis filas de espera nos postos médicos e percorrem grandes distâncias com seus filhos nos braços para conseguir o transporte.

Tanta energia feminina gasta para a reprodução social em áreas periféricas retira muito tempo de investimento para a qualificação para o mercado de trabalho. Como visto nos processos analisados, as mulheres mantinham ocupações, mesmo quando remuneradas, consideradas secundárias em relação aos seus maridos. Após uma dissolução conjugal, o quadro de dificuldades femininas aumenta substancialmente e isso está profundamente relacionado com o espaço urbano.

Embora várias mulheres tenham atividades remuneradas durante o período de conjugalidade, o papel feminino instituído socialmente prioriza a atuação da maternagem e do cuidado com a família. Após a dissolução conjugal, a falta de preparo feminino para assumir o sustento econômico, o abandono paterno, a falta de acesso à justiça, soma-se ainda o enfrentamento de uma estrutura urbana pouco favorável para a reorganização familiar em torno da figura feminina.

Assim como nos processos, as entrevistas realizadas e interpretadas por meio de análise de conteúdo, evidenciam que as espacialidades das mulheres, após a dissolução conjugal, sofre importantes transformações, havendo elementos de permanência e mudança. Os elementos de mudança e de permanência nas vivências espaciais das mulheres que passaram por dissolução conjugal evidenciam que a divisão entre o espaço público e privado torna-se inexistente, estabelecendo uma vivência espacial articulada, embora mutável em termos de relações de força.

Como elementos de permanência na vivência espacial das mulheres são as responsabilidades em torno dos filhos e da casa que já estavam presentes no período em que mantinham a situação conjugal. Além disso, é importante dizer que o trabalho fora de casa é um elemento de permanência para $66 \%$ das mulheres que figuravam nos processos analisados e em $70 \%$ das entrevistadas. A figura da mulher pobre e casada atuando apenas como dona de casa tendo o marido como o total provedor girou em torno de $30 \%$ em ambos os campos de exploração, processos e entrevistas. Assim, o trabalho figura como um elemento de permanência em muitas vidas femininas após a dissolução conjugal. Entretanto, ele muda de sentido pois se durante o período de conjugalidade o trabalho feminino é considerado uma renda complementar, na nova situação, ele é o fundamento da existência econômica da família. Os elementos de mudança estão relacionados ao sentimento de responsabilidade financeira e de autoridade moral para com os filhos e a sociedade, bem como o sentimento de liberdade e autonomia.

Imaginando o jogo escalar proposto por Souza (2006) e utilizando do conceito de espaço paradoxal de Rose (1993) pode-se argumentar que essas mulheres ocupam simultaneamente centro e margem das relações de poder, dependendo da escala espacial que é tomada por base de análise e da dimensão adotada.

A dimensão do trabalho, analisada na escala da casa, coloca a mulher como centro das necessidades da

Juliana Przybysz e J oseli Maria Silva 
Articulando os Espaços Público e Privado:Transformações das

Espacialidades Vividas por Mulheres Moradoras de Periferias Pobres

Após a Dissolução Conjugal na Cidade de Ponta Grossa - PR

família após a separação judicial. Contudo, ela ocupa posição de margem na estrutura urbana. A figura a seguir evidencia a formação do espaço paradoxal da posição feminina na dimensão do trabalho em que simultaneamente ocupa posição de centro e margem, dependendo da escala adotada.

As entrevistas evidenciam que a inserção laboral das mulheres, agora únicas responsáveis pelo sustento da família, é bastante precária. Após a dissolução conjugal, 37\% delas alegaram estar desempregadas,

Figura $1-$.

O Espaço paradoxal como componente do cuidado com os fihos, infraestrutura, renda e trabalho das mulheres que passaram por dissolução conjugal nos conjuntos habitacionais com maior concentração de mulheres chefes de familia em Ponta Grossa - PR.

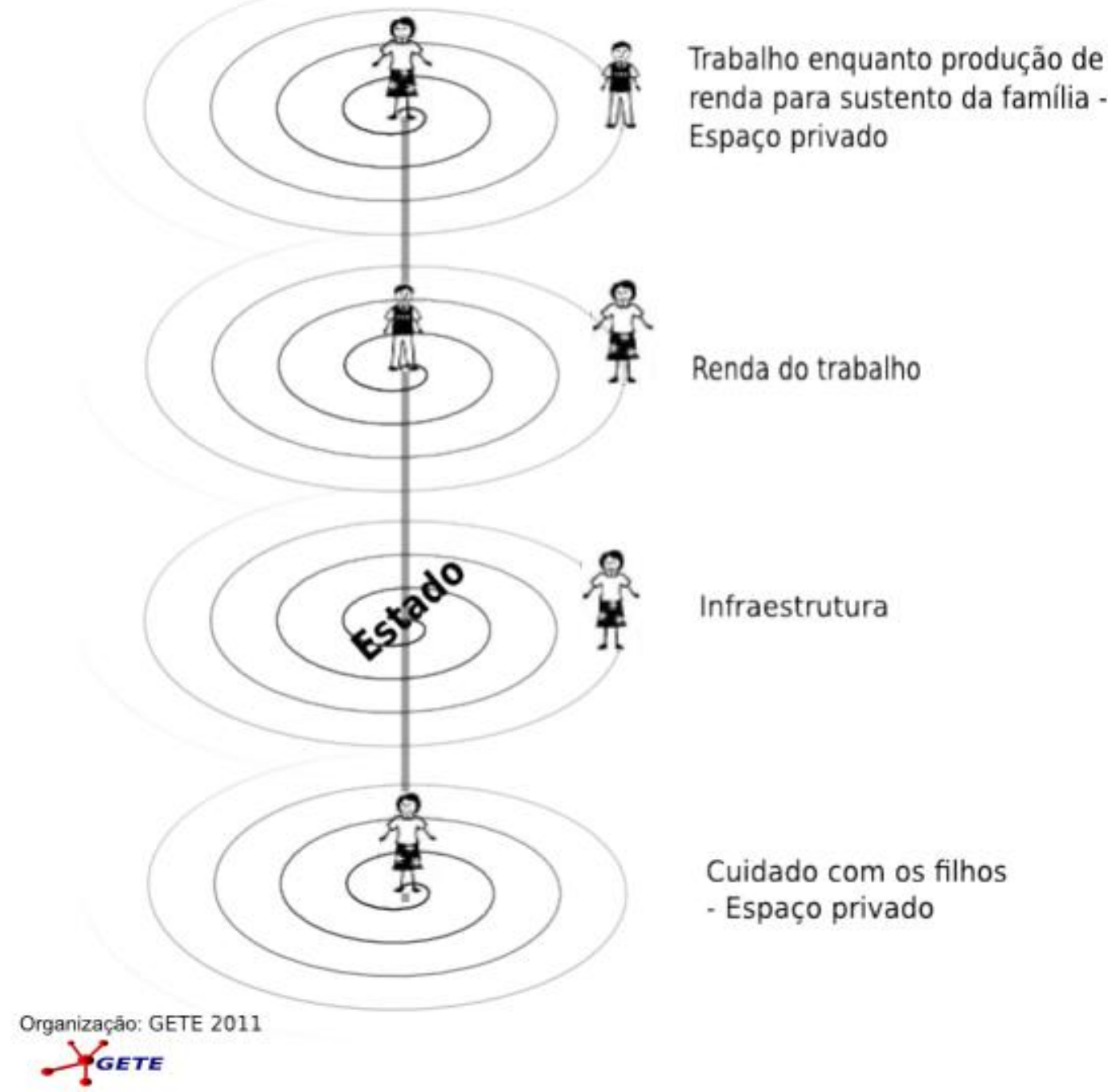

Fonte: Trabalho de campo realizado em 2010/2011

Juliana Przybysz e J oseli Maria Silva 
$30 \%$ considera-se empregada, trabalhando informalmente como diarista, $20 \%$ trabalha formalmente como mensalista nas atividades de domésticas ou cozinheiras e $13 \%$ é pensionista e aposentada.

A escolaridade é baixa no grupo de mulheres que foram entrevistadas, girando em torno de $40 \% \mathrm{com}$ ensino fundamental incompleto, $7 \%$ completo, $7 \%$ com ensino médio incompleto, $40 \%$ com ensino médio completo e $7 \%$ com ensino médio completo através do EJA, o que também dificulta muito uma melhora em sua situação laboral. Elas argumentam que os estudos possibilitariam uma melhora de suas perspectivas econômicas mas que deixaram de estudar muito cedo ao assumirem a maternagem e sua vida de casada, considerando incompatível o estudo e o desempenho de seu papel como esposa, pois em $42 \%$ das evocações um dos empecilhos para o estudo na fase adulta era o impedimento do marido. Agora, após a dissolução conjugal, como sua carga de trabalho dentro e fora de casa é muito pesada, não possuem apoio para deixar seus filhos para estudar e as escolas não são próximas de suas áreas de moradia, a volta aos estudos é quase impossível para elas. Assim, o grupo de mulheres investigadas não possuem uma posição de centralidade nos espaços escolares, apesar de que sua formação escolar é de fundamental importância para possibilitar ascensão social de todos os outros membros da família dependentes delas. Além disso, o espaço escolar também não acolhe as necessidades da mulher pobre e provedora exclusiva de sua família. A oferta de creches e escolas em tempo integral não estão disponíveis nas áreas de moradia das periferias pobres.

Como elas se constituem como sendo as únicas responsáveis economicamente pelos filhos, mas também são responsáveis pelo seu cuidado em uma área sem creches e escolas em tempo integral, não é incomum essas mulheres serem culpabilizadas pelo Conselho Tutelar por 'abandono de incapaz', pois, muitas vezes, deixam crianças sozinhas em casa para sair para o trabalho. O Estado pode retirar seus filhos e institucionalizá-los para protegê-los da 'mãe irresponsável'.

O estabelecimento de um contínuo entre as espacialidades pública e privada é claro nesta situação, pois a partir do momento em que tratamos a esfera doméstica como apenas um espaço de privacidade, deixamos de tratar enquanto uma espacialidade política. Cabe ressaltar, que quando somamos este fato ao papel feminino que é construído através da espacialidade privada, consequentemente, deixamos também de tratar as famílias monoparentais a partir de seu viés político.

As entrevistas realizadas nos conjuntos habitacionais, com alto percentual de chefia familiar feminina, evidenciam que a distância dessas áreas de serviços e infraestrutura afetam de forma contundente lares em que as mulheres são as únicas responsáveis pelo sustento das famílias. Os conjuntos habitacionais estão sendo entregues às famílias sem que haja nem mesmo linhas de ônibus com frequência necessária para o deslocamento dessas mulheres que em seu cotidiano, antes de se deslocarem ao local de trabalho, devem ir à outros bairros levar seus filhos para deixar em creches ou casa de parentes. Na volta para a casa o trajeto é o mesmo, tendo que primeiro recorrer aos outros bairros para buscar os filhos e só então se direcionar para suas casas. Vencer essas grandes distâncias percorridas é um desgaste que, muitas vezes, dificulta sua manutenção nos postos de trabalho.

A precariedade relacionada ao espaço público afeta diretamente o espaço privado, havendo um tencionamento mútuo entre elas, demonstrando que a permanência de uma linha divisória tratando cada espacialidade enquanto fechada prejudica intensamente a vivência destas mulheres.

Mesmo assim, a separação para estas mulheres é avaliada como algo que mudou sua vida em alguns aspectos positivos, por pior que tenham sido suas dificuldades. A liberdade e autonomia é um elemento marcante dos aspectos positivos da separação, bem como a conquista da casa própria nos conjuntos habitacionais, por mais precários que eles sejam em termos de infraestrutura.

De forma muito interessante, quando indagadas sobre as diferenças da vida de casada e da vida atual $87,5 \%$ das evocações foram colocadas em relação a melhora da vida após a dissolução conjugal, os motivos que levam a esta melhora são diversos nas falas do grupo e podem ser verificados no gráfico 2 a seguir.

Este gráfico permite observar que as falas relacionam a melhora de vida após a dissolução conjugal, mesmo frente à todas as adversidades vividas por elas e suas famílias. Apesar da falta de apoio do pai dos menores, elas afirmam que a autonomia, a possibilidade de administrar as despesas da casa faz com que o rendimento seja melhor aplicado para a melhoria das condições gerais da família. Alegam que sabem investir melhor na família do que seus exmaridos, inclusive a conquista de habitação, mesmo na periferia da cidade. A conquista do 'sossego' é resultado da libertação dos conflitos e agressões e a liberdade é poder ir e vir com autonomia. Essas conquistas parecem amenizar o sofrimento vivido e reunir forças para continuar sua luta.

Esses aspectos positivos estão relacionados à

Juliana Przybysz e J oseli Maria Silva 


\section{Articulando os Espaços Público e Privado: Transformações das \\ Espacialidades Vividas por Mulheres Moradoras de Periferias Pobres \\ Após a Dissolução Conjugal na Cidade de Ponta Grossa - PR}

Gráfico 2 - As principais diferenças entre a vida de casa e a vida após a separação das mulheres que passaram por dissolução conjugal nos conjuntos habitacionais com maior concentração de mulheres chefes de família em Ponta Grossa - PR.
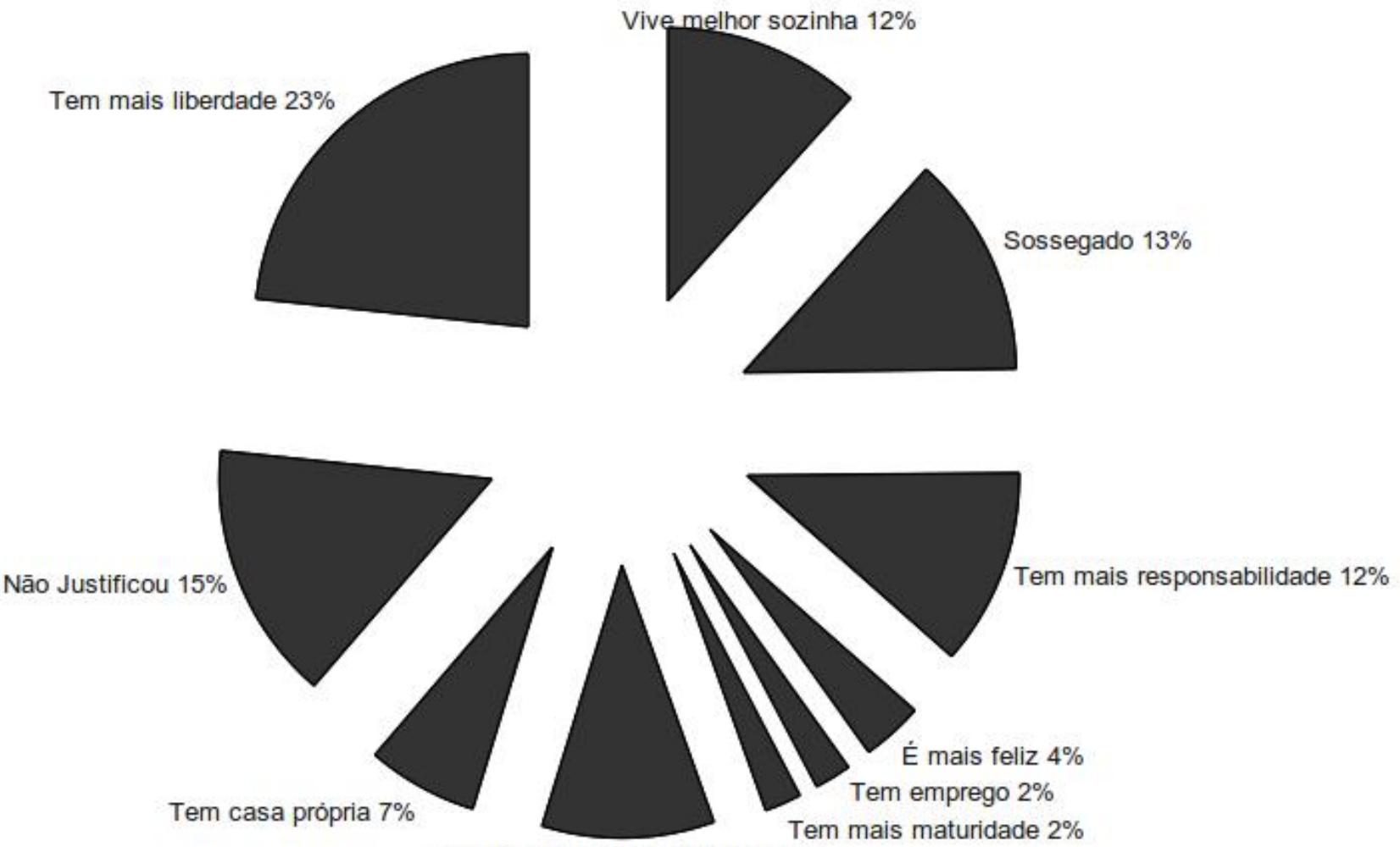

Administra melhor o dinheiro $10 \%$

Fonte: Trabalho de campo realizado em 2010/2011

Organização: Przybysz. J

família e ao sentimento individual, mas alegam que ainda sofrem preconceito por parte da sociedade por serem separadas em $69 \%$ das evocações sobre sua relação com a sociedade. Essa relação com a sociedade também é referida como falta de apoio por parte do Poder Público em 28\% das evocações das mulheres e em apenas 3\% delas referem-se ao apoio da sociedade.

A análise da vivência espacial dessas mulheres, articulada espacialmente por meio de escalas, permite evidenciar que a casa e as relações familiares estão imbricadas com a totalidade do espaço urbano. Suas experiências e lutas tensionam os papéis de gênero, ao mesmo tempo em que também os reproduzem. Assim, os espaços que elas produzem a partir de sua existência é relacional e múltiplo em posições de poder. $\mathrm{O}$ espaço que permeia este fenômeno é multidimensional e multiescalar, variando a posição feminina centro e margem de suas configurações de poder. Portanto, essa existência complexa das mulheres que colaboraram para esse estudo é um desafio para novas abordagens geográficas que superem a visão dicotômica entre público e privado, mas que contemple sua articulação complexa.

\section{Considerações Finais}

Este trabalho trouxe a compreensão das transformações das espacialidades vividas por mulheres responsáveis pelo domicílio após a dissolução conjugal na cidade de Ponta Grossa - PR. As mulheres das periferias pobres que passaram por dissoluções conjugais tem passado por transformações de seu papel de gênero na reorganização familiar, havendo mudanças e permanências de elementos presentes em sua existência espacial. Após a dissolução conjugal as mulheres têm assumido 
majoritariamente o sustento econômico de sua família, bem como, acumulado seu papel de cuidados com seus filhos. Esse acúmulo de tarefas tem sido pensado do ponto de vista privado por se tratar de uma questão familiar. Entretanto, sua existência nos mostra que a forma com que as famílias moradoras das periferias pobres estão se reorganizando, diz respeito ao aumento da vulnerabilidade social e econômica de grupos específicos e, portanto, isso é algo que diz respeito a toda a sociedade, devendo ser tratado de forma articulada com o espaço público.

Pensar espacialmente o empobrecimento das cidades contemporâneas brasileiras implica, urgentemente, em ampliar a visão relacional entre as escalas como sugere Souza (2006) e conceber as pessoas vivenciando o seu cotidiano de forma complexa, múltipla e em várias posições sociais. Manter a visão dicotômica entre o público e o privado, desprezando as articulações que dão sentido à existência cotidiana das mulheres pobres, apenas empobrece a capacidade geográfica de construir novas abordagens sociais e inteligibilidades espaciais.

1 A análise processual, na Segunda Vara de Família foi autorizada pelo juiz competente a ela, pois os processos referentes a família são beneficiados pelo segredo de justiça.

2 O Código Civil de 2003, embora haja alguns avanços do reconhecimento de famílias homoparentais, não contempla essa diversidade e mantêm a ideia de família constituída por homens, mulheres e filhos, como exemplos são os artigos. 1.514; 1.517; 1.565; 1567 e 1.632 .

3 Conforme Badinter (1985), a maternidade é o processo biológico de ser mãe e a maternagem é o cuidado com os filhos. Portanto, a maternagem não deve ser entendida apenas como um papel feminino mas pode ser executada por homens.

4 É importante lembrar que para este trabalho foi estipulado um recorte de grupo social tanto nos processos estudados quanto nas entrevistas realizadas nos conjuntos habitacionais. Sendo assim, foram consideradas as famílias sem renda até renda de dois salários mínimos com filhos menores de quatorze anos na época da separação.

\section{Referências}

ARENDT, Hanna. A condição humana. 10 Ed. Rio de Janeiro: Forense Universitária, 2007.
ASSIS, Mariana Pandrini Fraga. As esferas nos ajudam? Repensando a dicotomia público-privado na tradição feminista. In: Congresso da Associação de Estudos Latino-Americanos, 2009, Rio de Janeiro: LASA, 2009. p. 1-18. [Disponível em $<$ http://lasa.international.pitt.edu/members/congresspapers/lasa2009/> Acesso em 25 de novembro de 2009]

BADINTER, Elizabeth. O amor conquistado- o mito do amor materno. Rio de Janeiro. Nova Fronteira. 1985 .

BARDIN, Laurence. Análise de conteúdo. Lisboa: Edições 70, 2002.

BUTLER, Judith. Problemas de gênero. Rio de Janeiro: Civilização Brasileira, 2003.

CORRÊA, Roberto Lobato; ROSENDAHL, Zeny. Introdução a Geografia Cultural. Rio de Janeiro: Bertrand Brasil, 2003.

CORRÊA, Roberto Lobato. O espaço urbano. 4. ED. São Paulo: Ática, 2003.

FERES-CARNEIRO, Terez. Casamento e Família: do social à clínica. Rio de Janeiro: Nau Editora, 2001.

GOHEEN, Peter G. Public space and the geography of the modern city. Progress in Human Geography, v. 22, n. 4, p. $479-496,1998$.

GOMES, Paulo Cesar da Costa. A condição urbana: ensaios de geopolítica da cidade. Rio de Janeiro: Bertrand Brasil, 2002.

HIDALGO, Encarna; JULIANO, Dolores; ROSET, Montserrat; CABA, Àngels. Repensar la enseñanza de la geografía y la historia: una mirada desde el género. Barcelona: Editorial Octaedro, 2003.

HOWITT, Richard. Scale as relation: musical metaphors of geographical scale. Area, v. 30, n. 1, p. 49-58, 1998.

MASSEY, Doreen. Pelo Espaço: Uma Nova Política da Espacialidade. Rio de Janeiro: Bertrand Brasil, 2008.

MCDOWELL, Linda. Gender, Identity and Place: Understanding Feminist Geographies. Cmabridge: Potity Press, 1999. 
Articulando os Espaços Público e Privado: Transformações das

Espacialidades Vividas por Mulheres Moradoras de Periferias Pobres

Após a Dissolução Conjugal na Cidade de Ponta Grossa - PR

MARSTON, Sallie A. The social construction of scale.

Progress in Human Geography, v. 24, n. 2, p.

219-242, 2000.

MITCHELL, Don. Introduction: Publico Space and the city. Urban Geography, v. 17, n. 2, p. 127-131, 1996.

ROSE, Gillian. Feminism \& geography: the limits of geographical knowledge. Cambridge: Polity Press, 1993.

SANTOS, Milton. Espaço e método. São Paulo: Nobel, 1985.

1987.

O espaço do cidadão. São Paulo: Nobel,

SHEPPARD Eric; MCMASTER, Robert. Scale and Geographic Inquiry: Nature, Society and Method. Malden - USA: Blechwell, 2004, p. 170 - 191.

SILVA, Joseli Maria. Amor, paixão e honra como elementos da produção do espaço cotidiano. Espaço e cultura, n. 22, p. 97-109, 2007.

Fazendo geografias: pluriversalidades sobre gênero e sexualidades. In: SILVA, Joseli Maria. (Org.). Geografias subversivas: discursos sobre espaço, gênero e sexualidades. Ponta Grossa: Editora Todapalavra, 2009, p. 25-53.

SILVA, Joseli Maria, CHIMIN JUNIOR, Alides Baptista, PERACETTA FILHO, Emilson e ROSSI, Rodrigo. Geografia e Gênero no Brasil: uma análise da feminização do campo científico. Ateliê Geográfico. v. 3, n. 7, p. 38-62, 2009.

SORJ, Bila. Trabalho remunerado e trabalho não remunerado. In: VENTURINI, Gustavo; RECAMÁN, Marisol; OLIVEIRA, Suely (Orgs). A mulher brasileira nos espaços público e privado. São Paulo: Ed. Fundação Perseu Abramo, 2004, p. 247.

SOUZA, Marcelo Lopes de. A prisão e a Ágora: Reflexões em torno do planejamento e da Gestão das Cidades. Rio de Janeiro: Bertrand Brasil, 2006.

VELEDA DA SILVA, Susana. A perspectiva feminista na geografia brasileira. In: SILVA, Joseli Maria. (Org.). Geografias subversivas: discursos sobre espaço, gênero e sexualidades. Ponta Grossa: Editora Todapalavra, 2009, p. 301-313.

Recebido em 30 de setembro de 2011. Aceito em 27 de dezembro de 2011.

Juliana Przybysz e J oseli Maria Silva 